\title{
Increased expression of markers of early atherosclerosis in patients with inflammatory bowel disease is
}

\author{
Maria Cappello ${ }^{\mathrm{a}, *, 1}$, Anna Licata ${ }^{\mathrm{a}, 1}$, Vincenza Calvaruso ${ }^{\mathrm{a}}$, Ivana Bravatà ${ }^{\mathrm{a}}$, Alessandra Aiello ${ }^{\mathrm{a}}$, Daniele Torres ${ }^{\mathrm{b}}$, \\ Vittoriano Della Corte ${ }^{\mathrm{b}}$, Antonino Tuttolomondo ${ }^{\mathrm{b}}$, Maria Perticone ${ }^{\mathrm{c}}$, Giuseppe Licata ${ }^{\mathrm{b}}$, \\ Antonio Craxì ${ }^{\text {, }}$, Calogero Cammà ${ }^{\text {a }}$
}

a Gastroenterology and Hepatology Section, DIBIMIS, University of Palermo School of Medicine, Palermo, Italy

${ }^{\mathrm{b}}$ Internal Medicine and Cardioangiology, DIBIMIS, University of Palermo School of Medicine, Palermo, Italy

c Department of Experimental and Clinical Medicine, University of Magna Græcia of Catanzaro, Italy

\section{A R T I C L E I N F O}

\section{Article history:}

Received 24 August 2016

Received in revised form 1 October 2016

Accepted 6 October 2016

Available online $\mathrm{xxxx}$

\section{Keywords:}

Arterial stiffness

IBD

Carotid intima-media thickness

Early atherosclerosis

\begin{abstract}
A B S T R A C T
Background E Aims: Recent studies documented an increased cardiovascular risk in patients with inflammatory bowel disease (IBD). Our study aimed at investigating the prevalence of intima-media thickness (IMT) of the carotid arteries and the arterial stiffness indices as markers of early atherosclerosis in young IBD patients.

Methods: We recruited 68 consecutive IBD patients, and 38 matched healthy controls less than 45 years old (median age $31.6 \pm 8.1$ years). Clinical and demographic features, cardiovascular risk factors, history of cardiovascular events, concomitant therapies were registered on a dedicate database. Carotid IMT was evaluated by using high resolution B-mode ultrasonography. Arterial stiffness was assessed by measurement of carotidfemoral Pulse Wave Velocity (PWV) and Augmentation Index (AIx).

Results: Total cholesterol $(P<0.013)$ and LDL-cholesterol $(P<0.019)$ levels were significantly lower in IBD patients compared to controls. Carotid IMT was higher in IBD than in controls $(P<0.047)$, but there was no statistically significant difference among Crohn's Disease (CD) and Ulcerative Colitis (UC) patients. Moreover, PWV and AIx were significantly higher in patients as compared to controls $(P<0.006$ and $P<0.004$ respectively). No medication seemed to affect vascular measurements, though stiffness parameters were significantly higher in patients treated with 5-ASA (11.9 (9.7) vs $18.2(10.2), P<0.021)$, suggesting a lack of efficacy of 5-ASA in protecting IBD patients from early atherogenesis.

Conclusions: Young IBD patients show an increase in subclinical markers of atherosclerosis. Future studies need to address whether these markers result in an increased risk of cardiovascular events in these patient.
\end{abstract}

(c) 2016 European Federation of Internal Medicine. Published by Elsevier B.V. All rights reserved.

\section{Introduction}

Inflammatory bowel diseases (IBD), Crohn's Disease (CD) and Ulcerative Colitis (UC), are chronic inflammatory disorders of the gastrointestinal tract. Pathogenesis may be the result of interaction between environmental factors and intestinal bacteria in genetically predisposed individuals, which may give rise to an aberrant immune response leading to bowel damage [1].

Abbreviations: IBD, Inflammatory bowel disease; CD, Crohn's Disease; UC, Ulcerative Colitis; IMT, Intima media thickness; PWV, Pulse wave velocity; AIx, Augmentation index; DBP, Diastolic blood pressure; SBP, Systolic blood pressure; FMD, Flow mediated dilation; ESR, Erythrocyte-sedimentation rate; CRP, C-reactive protein.

it Source of support: none.

* Corresponding author at: Gastroenterology \& HepatologySection, Dipartimento Biomedico di Medicina Interna e Specialistica, Piazza Delle Cliniche 2, 90127 Palermo, Italy.

E-mail address: marica.cappello61@gmail.com (M. Cappello).

1 Those authors equally contributed to this paper.
Several studies have investigated the association between IBD, cardiovascular and thromboembolic disease [2-3]. Recently, researchers have focused on cardiovascular risk and on the possibility of early onset and rapid progression of the atherosclerotic process, with conflicting results [4-9].

Atherosclerosis is a pathological condition mainly characterized by loss of elasticity of arterial walls. Atherogenesis is a chronic inflammatory process of the arterial wall, finally leading to endothelial dysfunction $[10,11]$, which involves the alteration of the control of the vascular tone, leukocytes trafficking and platelets adhesion. The risk of early onset of atherosclerosis is well known in individuals suffering from other chronic inflammatory disorders such as rheumatoid arthritis and systemic lupus erythematosus [12-14], thus it should not be surprising that, in the last decade, an increasing body of data, both epidemiological and clinical, have supported this association also in IBD.

Epidemiological studies on incidence of cardiovascular events in patients with IBD have led to discrepant results [15-19]. A retrospective 
study from North America [16] showed that the incidence of coronary artery disease in patients with IBD was higher as compared to a control group, in spite of a low incidence of traditional risk factors (smoking, diabetes, hypertension and hypercholesterolemia). Two Danish nation-wide cohort studies demonstrated an increased risk of ischemic heart disease and also showed that the risk was lower in those treated with 5-ASA [17,20]. Finally, a systematic review has confirmed the key role of chronic inflammation in causing progression of the atherosclerotic process and thus, coronary risk in IBD [19].

From a clinical point of view, the assessment of early atherosclerosis has been made by investigating surrogate markers such as the carotid artery intima-media thickness (IMT), flow-mediated vasodilatation of the brachial artery (FMD) and arterial stiffness by pulse wave velocity (PWV) [21-30]. The study by Aloi et coll, reported signs of endothelial dysfunction and early atherosclerosis even in children with IBD [27]. Zanoli et al. reported results from two studies $[29,30]$ carried on IBD adult patients evaluated by measuring arterial stiffness, the first being a cross-sectional study, the second evaluating the effect of long-term therapy. Both studies showed that there was an increase in both carotid-radial and carotid-femoral PWV in IBD patients as compared with controls and that arterial stiffness of these patients was related to the degree of inflammation and reduced by immunomodulatory drugs. More recently, Ozturk et al. [31] added further evidence to the association of early atherosclerosis markers and IBD by investigating arterial stiffness, FMD and IMT, showing a significant relationship between disease duration and hemodynamic parameters.

In the current cross-sectional study, we aimed to demonstrate in a homogeneous prospective Mediterranean cohort of young IBD patients (aged less than 45 years) early signs of atherosclerosis through the assessment of IMT of the carotid arteries and of arterial stiffness studied by PWV and Augmentation Index (AIx). Furthermore, we tried to evaluate whether 5-aminosalicilyc acids (5-ASA), steroids, immunosuppressant drugs and biologics could affect hemodynamic parameters.

\section{Materials and methods}

\subsection{Patient's selection}

One hundred-six subjects aged between 17 and 45 years have been enrolled from September 2012 until December 2013; sixty-eight were patients consecutively diagnosed as suffering from IBD and attending our IBD outpatient clinic and 38 were healthy individuals enrolled as age and sex-matched controls. Written informed consent for participation in the study was obtained from both patients and controls.

Clinical and demographic data were recorded in a dedicated database. Clinical data included: age, gender, family history of IBD, co-morbidities, (e.g. diabetes and/or hypertension), traditional risk factors for the onset of atherosclerosis (Blood Pressure, Body Mass Index, smoking, TotalCholesterol, Triglycerides, LDL-Cholesterol, HDL-Cholesterol), disease features (IBD type, extent, extra-intestinal manifestations, previous surgery), disease activity assessed by Mayo Score [32] for UC and the Harvey Bradshaw Index for CD [33], C-reactive protein (CRP) values, concomitant drug therapies. A blood sample was drawn for the evaluation of lipid profile and other laboratory parameters.

On recruitment, traditional risk factors were evaluated for both cases and controls on the basis of the criteria shown below. Smoking habit was explored and recorded in the database. Hypercholesterolemia was defined as the presence of total cholesterol blood levels $\geq 200 \mathrm{mg} / \mathrm{dL}$. Hypertension was defined as present, if subjects has been previously diagnosed according to the World Health Organization/International Society of Hypertension guidelines and were routinely receiving antihypertensive therapy. Patients were defined as type 2 diabetics if they had diabetes treated by diet, or if they were taking oral hypoglycemic drugs or insulin. Individuals with already known cardiovascular disease (coronary heart disease, stroke, transient ischemia attack) were excluded.
Standard laboratory parameters, including CRP and erythrocytesedimentation rate (ESR), were measured in the blood at time of hemodynamic measurements. All participants were evaluated in a quiet room, where non-invasive assessment of hemodynamic parameters was performed by an expert physician blinded to clinical information, including therapy. Another physician, blinded to hemodynamic measurements, collected and recorded all clinical data of enrolled patients and controls.

\subsection{Carotid artery evaluation}

Carotid atherosclerosis was assessed by an expert physician (D.T.) using high-resolution B-mode ultrasonography equipped with a multifrequency linear probe. Carotid arteries were investigated in longitudinal projections of both the left and right side, at the level of the common carotid artery, of the bulb and of the internal carotid. Carotid IMT was measured as the difference between a first interface (lumenintima) and a second interface (media-adventitia), along the wall of the common carotid artery, in a free section of plate, for $10 \mathrm{~mm}$ upstream and $10 \mathrm{~mm}$ downstream of their bifurcations. For each subject, three measurements were made on both sides, projection in front side and rear, and were made an average of the measurements. A carotid plaque was defined the finding of a focal thickening of $>1.3 \mathrm{~mm}$ at the level of the common carotid arteries and their bifurcations. The operator assessed the intra-observer variability repeating in two different times the carotid IMT measurements in ten IBD patients and five controls randomly chosen. The concordance coefficient between the intra-observer evaluations was 0.97 . The inter-observer evaluation was not calculated because all measurements were performed by the same operator.

\subsection{Pulse wave velocity assessment}

Examinations were carried out by an expert physician (V.D.C.), after 15 min of rest, carefully following the directions given for a correct standardization of the conditions of the subjects examined. Approximately every $2 \mathrm{~min}$, blood pressure was checked at the level of the brachial artery (DinamapProCare 100; GE Healthcare).

The values of the central pressures were recorded in a non-invasive manner through the applanation tonometry (SphygmoCor; AtCor Medical, Sydney, Australia). Carotid-femoral PWV was measured in the supine position using the automatic device (SphygmoCor version 7.1) that measured the time delay between the rapid upstroke of the carotid and femoral artery pulse waves. The distance between the two arterial points was measured on the surface of the body using a tape measure. PWV was calculated as the distance travelled by the arterial pulse wave (meters) divided by the time delay between the two arterial points (seconds), thus expressed as meters per second $(\mathrm{m} / \mathrm{s})$. The "distance between the two arterial points" was measured using the total distance between the carotid and femoral sites of measurement [34,35].

PWV assessment has been repeated in two different times in ten IBD patients and five controls randomly chosen. The concordance coefficient between the intra-observer evaluations was 0.96 . The inter-observer evaluation was not calculated because all measurements were performed by V.D.C.

\subsection{Pulse wave analysis}

Applanation tonometry was used to record radial arterial pressure waveform continuously, and mean values of $\geq 2$ screens of pulse waves of good quality were used for analysis. On the basis of the collected data, an averaged radial pressure waveform was generated and a corresponding aortic pressure waveform and blood pressure calculated by the validated transfer function. The aortic pressure waveform was used to calculate the Aortic AIx (difference in height between 
the first (P1) and second (P2) systolic peaks expressed as a percentage of pulse pressure (PP) [36]).

\subsection{Statistical analysis}

Continuous variables were expressed as mean \pm standard deviation, and categorical variables as absolute frequency and percentage. The comparison between continuous variables was made by the Student's $t$-test and categorical variables were analysed by using the chi-square test. Multivariate logistic regression analysis was used to assess the relationship between the use of 5-ASA and the arterial stiffness parameters. Statistical significance was reached when $P$ was $<0.05$. Data obtained were analysed using the software SPSS (Statistical Package for Social Science) ver. 15.0.

\section{Results}

We enrolled 106 subjects: 68 IBD patients (males 51.5\%), mean age of $31.6 \pm 8.1$ years (range 17-45 years) and 38 healthy individuals' age and sex matched as controls. Demographic, clinical and laboratory features of IBD patients and controls are summarized in Table 1.

Among IBD patients, 45 (66\%) had CD, of whom 22 (48\%) had a disease duration greater than 5 years, $9(20 \%)$ showed a clinically active disease; 23 (33\%) were suffering from UC, 8 (35\%) of these had a disease duration greater than 5 years and 3 showed a clinically active disease. Overall, mean disease duration was $5.0 \pm 4.3$ years. Among IBD patients, $13(19.1 \%)$ had a family history of IBD. As for the traditional risk factors for cardiovascular events, 16 (23.5\%) patients were smokers; 9 (13\%) ex-smokers; 29 (42\%) had a family history of cardiovascular events, 3 were hypertensive and 2 patients had diabetes mellitus, 21 had a BMI greater than 25. Markers of inflammation, such as CRP and ESR, were evaluated only in IBD patients.

IBD features of the study population are shown in Supplementary Table. Nine out of $45 \mathrm{CD}$ patients (22\%) had an ileal localization, $71.1 \%$ and $2.2 \%$ had ileo-colic and colic respectively, $6.7 \%$ had an upper digestive tract involvement (stomach and/or duodenum and/or jejunum), $37.8 \%$ had not stricturing not fistulising behaviour, 35.5\% had stricturing, $13.3 \%$ fistulizing, $6.7 \%$ stricturing and fistulizing and $6.7 \%$ had perianal disease. Among 23 patients with UC, 34.8\% had proctosigmoiditis, 47.8\% left colitis and $17.4 \%$ pancolitis. Extra-intestinal manifestations were present in $31 \%$ of $C D$ patients and in $13 \%$ with UC. At the time of recruitment, $62 \%$ of patients with $\mathrm{CD}$ were treated with mesalamine, $27 \%$ with steroids, $35.5 \%$ with immunosuppressants and $29 \%$ were on biological therapy (infliximab or adalimumab), while among the UC patients $91.3 \%$ were taking mesalamine, $26 \%$ steroids, immunosuppressants $30.4 \%$, and $8.7 \%$ were on biologics (infliximab or adalimumab).

\subsection{Comparison between IBD patients and healthy controls}

There were no statistically significant differences between patients and controls as concerns family history of cardiovascular events, smoking habits, diabetes and hypertension. There was a trend toward significance in the distribution of body mass index values between patients and controls ( $22 \pm 3.8$ versus $24 \pm 4.4, P=0.082)$. A statistically significant difference was found for the values of total cholesterol (159, $9 \pm 32,8 \mathrm{mg} / \mathrm{dl}$ vs $176,9 \pm 35.7 \mathrm{mg} / \mathrm{dl}, P=0.015)$ and LDL-cholesterol $(90,1 \pm 27.2 \mathrm{mg} / \mathrm{dl}$ vs $103,9 \pm 33.5, P=0.023)$ which were lower in IBD patients. There was no difference in lipid profile between $\mathrm{CD}$ and UC.

\subsection{Hemodynamic measurements in IBD patients and controls}

Table 1 presents the results regarding values of IMT and arterial stiffness of carotid artery. The average carotid IMT was higher in patients with IBD than in controls $(0.5 \pm 0.2$ vs $0.4 \pm 0.1, P=0.047)$ (Fig. 1), any statistically significant difference in carotid IMT was
Table 1

Clinical-demographic and biochemical features of IBD patients and controls.

\begin{tabular}{|c|c|c|c|}
\hline & $\begin{array}{l}\text { IBD Patients } \\
(\mathrm{N}=68)\end{array}$ & $\begin{array}{l}\text { Controls } \\
(\mathrm{N}=38)\end{array}$ & $P$ \\
\hline Age (mean - SD) & $31.6(8.1)$ & $30.4(6.3)$ & 0.395 \\
\hline \multicolumn{4}{|l|}{ Gender } \\
\hline Males & 35 & 18 & \multirow[t]{2}{*}{0.685} \\
\hline Females & 33 & 20 & \\
\hline \multicolumn{4}{|l|}{$\begin{array}{l}\text { Familial predisposition } \\
\text { for IBD }\end{array}$} \\
\hline No & 55 & - & \\
\hline Yes & 13 & - & \\
\hline \multicolumn{4}{|l|}{ Familial predisposition for } \\
\hline No & 39 & 26 & \multirow{2}{*}{0.262} \\
\hline Yes & 29 & 12 & \\
\hline \multicolumn{4}{|l|}{ Smoking habit } \\
\hline No & 43 & 25 & \multirow[t]{2}{*}{0.994} \\
\hline Yes & 24 & 14 & \\
\hline \multicolumn{4}{|l|}{ BMI } \\
\hline Mean - SD & $22.5(3.8)$ & $23.9(4.4)$ & 0.082 \\
\hline \multicolumn{4}{|l|}{ Hypertension } \\
\hline No & 65 & 37 & \multirow[t]{2}{*}{0.645} \\
\hline Yes & 3 & 1 & \\
\hline \multicolumn{4}{|l|}{ Diabetes } \\
\hline No & 66 & 37 & \multirow[t]{2}{*}{0.927} \\
\hline Yes & 2 & 1 & \\
\hline \multicolumn{4}{|l|}{ Carotid IMT mean $(\mathrm{mm})$} \\
\hline Right (range) & $0.5(0,2)$ & $0.4(0,1)$ & 0.047 \\
\hline Left (range) & $0.5(0,1)$ & $0.6(0,7)$ & 0.468 \\
\hline \multicolumn{4}{|l|}{ Carotid Plaque } \\
\hline No & 60 & 34 & \multirow[t]{2}{*}{0.129} \\
\hline Yes & 8 & 1 & \\
\hline \multicolumn{4}{|l|}{ AORTIC AIx (AP/PP) } \\
\hline Mean (SD) & $16.4(10.4)$ & $11.0(7.8)$ & 0.004 \\
\hline $\begin{array}{l}\text { AORTIC AIx (P2/P1) } \\
\text { Mean (SD) }\end{array}$ & $121.9(16.3)$ & $110.5(19.3)$ & 0.002 \\
\hline $\begin{array}{l}\text { PWV (cut-off) } \\
\quad(\text { Mean - SD) }\end{array}$ & $8.7(1.3)$ & $8.0(1.2)$ & 0.006 \\
\hline SBP & & & 0.878 \\
\hline (Mean - SD) & $118.1(18.3)$ & $117.6(12.8)$ & \\
\hline \multicolumn{4}{|l|}{ DBP } \\
\hline (Mean - SD) & $74.5(13.8)$ & $75.3(11.6)$ & \multirow[t]{6}{*}{0.755} \\
\hline WBC (mean - SD) & $7100(2610)$ & - & \\
\hline $\mathrm{ESR}($ mean - SD) & $14.3(12.8)$ & _- & \\
\hline CRP (mean - SD) & $8.4(32.6)$ & - & \\
\hline PLT (mean - SD) & 283926 (94105) & - & \\
\hline $\mathrm{Hb}($ mean $-\mathrm{SD})$ & $13.4(1.7)$ & - & \\
\hline Total Cholesterol, (mean - SD) & $159.9(32.8)$ & $176.9(35.7)$ & 0.015 \\
\hline HDL Chol & $52.2(15.4)$ & $56.7(18.1)$ & 0.176 \\
\hline LDL Chol & $90.1(27.2)$ & $103.9(33.5)$ & 0.023 \\
\hline Triglycerides (mean - SD) & $93.4(40.0)$ & $81.1(44.9)$ & 0.152 \\
\hline
\end{tabular}

found between subjects with CD and UC. The presence of a plaque was observed in eight patients, while only in one control subject.

Regarding parameters related to arterial stiffness, PWV values were significantly higher in IBD patients as compared to controls ( $8.7 \pm 1.3 \mathrm{vs}$ $8.0 \pm 1.2, P=0.006)$; values of Aortic AIx (AP/PP) were increased in patients with IBD as compared with healthy controls (16.4 \pm 10.4 vs $11 \pm 7.8, P=0.004$ ), as well (See Figs. 2 and 3). Values of systolic and diastolic BP were normal in both groups, patients and controls.

\subsection{Impact of disease features and pharmacological therapy on hemodynamic measurement}

Regarding all hemodynamic measurements, no significant differences between patients with CD and UC have been shown (Table 2). In addition, no significant differences have been found between values of IMT, PWV and Aortic Aix among IBD patients in relation to disease duration and activity. In fact, although the Mayo Score [32] and the Harvey Bradshaw Index [33] are indices widely used in clinical trials, they do not really reflect the control of mucosal 


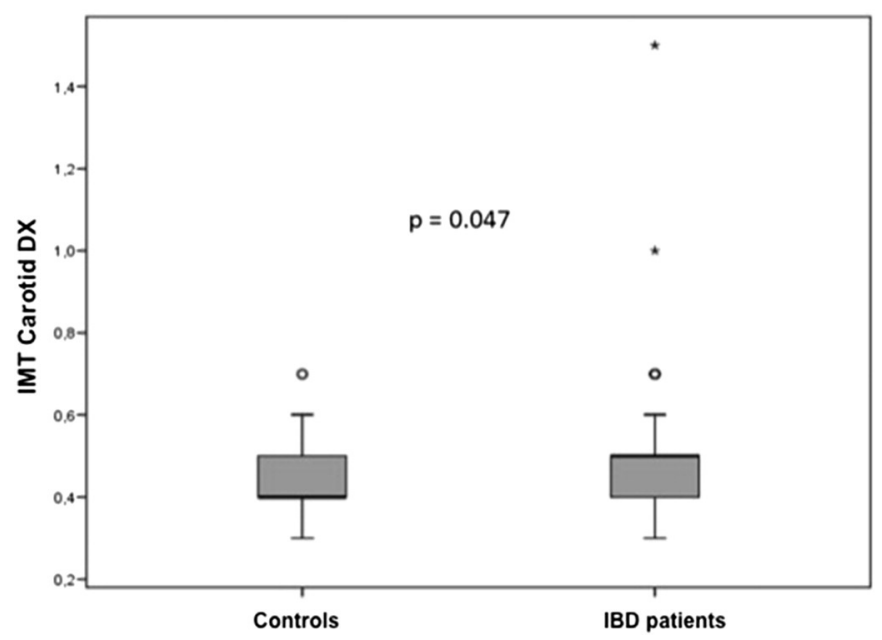

Fig. 1. IMT values of IBD patients as compared with healthy controls.

inflammation and need to be integrated by biomarkers and endoscopic scores. In addition, the absence of correlation between disease duration and hemodynamic measurements was also confirmed by linear regression analysis. Age, was significantly related to increasing values of all hemodynamic parameters, as expected (Table 3).

Impact of pharmacological therapy was separately analysed, as shown in Table 4.

A statistically significant relationship between the use of 5-ASA and stiffness parameters (Aortic Aix, AP/PP) was observed (18.2 \pm 10.2 vs $11.9 \pm 9.7, P=0.021)$; further, this association was confirmed in a multivariate logistic regression analysis (OR 1.08, CI 95\% 1.01-1.15, $P=0.019$ ); on the contrary, the same relationship could not be demonstrated for the distribution of IMT and other arterial stiffness values. Finally, the use of steroids, immunosuppressants and biologics did not correlate with hemodynamic measurements.

\section{Discussion}

Our study explored the hypothesis of early onset atherosclerosis in young patients with IBD, through the assessment of the prevalence of increased IMT and of higher values of arterial stiffness, in comparison to a group of healthy controls. We showed in a homogeneous cohort of Mediterranean young IBD patients, as far as concerns ethnic origin, a mild increase in the values of carotid IMT and the alteration of both parameters exploring the elastic properties of the arterial wall (PWV and Aortic AIx) compared to healthy controls, age and sex matched.

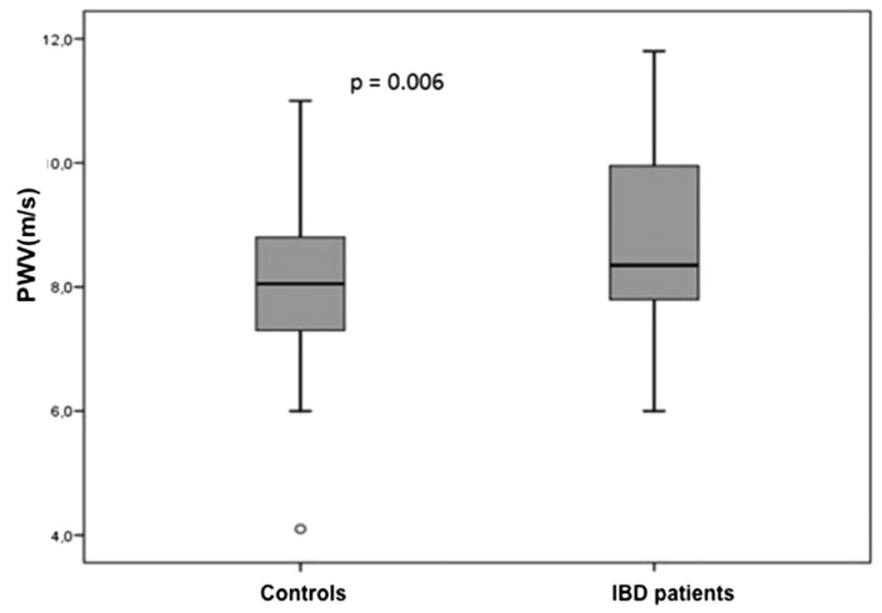

Fig. 2. Comparison of PWV values of IBD patients and healthy controls.

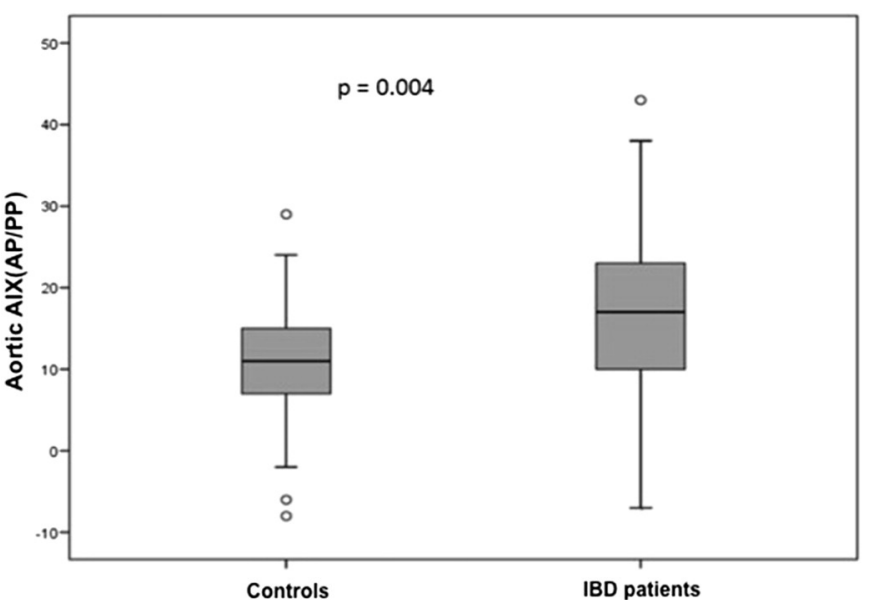

Fig. 3. AIx values (AP/PP) of IBD patients as compared with healthy controls.

Interestingly, in our patients the carotid IMT values, while showing levels classifiable in the "so-called" normal range (IMT $<1.3 \mathrm{~mm}$ ) were significantly higher than in healthy controls $(P<0.042)$. Our data confirm the results of most studies conducted in Mediterranean area [27-30], though other studies, carried out in Israel obtained opposite results [22-23]. We could speculate that ethnicity might have an influence on the risk of atherogenesis, being higher in population from Italy and Turkey, as compared with population from Israel, even if, we do not have any genetic markers to support our hypothesis.

Values of PWV and the Aortic AIx, such as the carotid IMT, were also significantly higher in our patients with IBD, although falling always within the normal range $(<12 \mathrm{~mm} / \mathrm{s}$ for PWV) in agreement with the results obtained by Zanoli $[29,30]$. Ozturk et al. found significant increase in PWV in a rather large sample but they were not able to evidentiate a difference in IMT [31]. In our study, we assessed arterial stiffness, not only by PWV, but also by central AIx. To our knowledge, ours is the only study assessing the arterial stiffness both by PWV and AIx in this clinical setting. In particular, central AIx respect to peripheral AIx, represents an element that suggests an earlier impairment of the elastic property of arterial wall and therefore it is likely to be considered a more reliable marker of "elastic dysfunction" and index of early atherosclerosis in these patients. Indeed, discrepant results of studies investigating markers of sublinical atherosclerosis could also be related to the different accuracy of vascular parameters in relation to the progression of atherosclerosis. Regarding to this, flow-mediated vasodilatation reflects early changes of the endothelium function, followed by

Table 2

Clinical and haemodynamic assessment of IBD patients in relation to IBD type.

\begin{tabular}{llll}
\hline & MC (45) & UC (23) & $P$ \\
\hline Age (mean - SD) & $32.2(7.3)$ & $30.6(9.7)$ & 0.486 \\
Gender (male) & $20(\%)$ & $15(\%)$ & 0.105 \\
Duration of disease > 5 years & $22(\%)$ & $8(\%)$ & 0.268 \\
Age $\geq 25$ years & $36(\%)$ & $15(\%)$ & 0.183 \\
Extra-intestinal manifestations & $14(\%)$ & $3(\%)$ & 0.094 \\
Active disease & $9(20 \%)$ & $10(43.5 \%)$ & $\mathbf{0 . 0 4 1}$ \\
ESR (mean - SD) & $15.5(13.9)$ & $12.0(9.9)$ & 0.299 \\
CRP (mean - SD) & $11.3(39.8)$ & $2.8(4.2)$ & 0.163 \\
IMT carotid right (mean - SD) & $0.5(0.1)$ & $0.5(0.2)$ & 0.490 \\
IMT carotid left (mean - SD) & $0.5(0.1)$ & $0.5(0.1)$ & 0.961 \\
Aortic Alx (AP/PP) & $16.8(11.0)$ & $15.6(9.4)$ & 0.656 \\
Aortic AIx (P2/P1) & $122.2(17.4)$ & $121.3(14.4)$ & 0.831 \\
PWV (m/s) & $8.6(1.3)$ & $9.1(1.4)$ & 0.136 \\
SBP (mean - SD) & $117.2(20.3)$ & $119.9(13.9)$ & 0.527 \\
DBP (mean - SD) & $72.6(12.6)$ & $78.2(15.6)$ & 0.115 \\
Total cholesterol (mean-SD) & $157.3(31.5)$ & $165(35.4)$ & 0.363 \\
Triglycerides (mean-SD) & $89.4(33.4)$ & $101.0(50.6)$ & 0.263 \\
\hline
\end{tabular}


Table 3

Relationship between haemodynamic measurements and disease features (duration and activity) of IBD patients.

\begin{tabular}{|c|c|c|c|c|c|c|c|c|c|}
\hline & $\begin{array}{l}\text { Age }<25 \text { years } \\
(17)\end{array}$ & $\begin{array}{l}\text { Age }>25 \text { years } \\
(51)\end{array}$ & $P$ & $\begin{array}{l}\text { No active disease } \\
\text { (49) }\end{array}$ & $\begin{array}{l}\text { Active disease } \\
\text { (19) }\end{array}$ & $P$ & $\begin{array}{l}\text { Disease }<5 \text { years } \\
(38)\end{array}$ & $\begin{array}{l}\text { Disease }>5 \text { years } \\
(30)\end{array}$ & $P$ \\
\hline \multicolumn{10}{|c|}{ Carotid IMT mean (mm) } \\
\hline Right (range) & $0.5(0.3)$ & $0.5(0.1)$ & 0.934 & $0.5(0.2)$ & $0.5(0.1)$ & 0.879 & $0.5(0.2)$ & $0.5(0.1)$ & 0.708 \\
\hline Left (range) & $0.4(0.1)$ & $0.5(0.2)$ & $<0.001$ & $0.5(0.1)$ & $0.6(0.2)$ & 0.172 & $0.5(0.2)$ & $0.5(0.1)$ & 0.513 \\
\hline \multicolumn{10}{|l|}{ CarotidPlaque } \\
\hline No & 16 & 44 & & 43 & 17 & & 35 & 25 & \\
\hline Yes & 1 & 7 & 0.385 & 6 & 2 & 0.844 & 4 & 4 & 0.654 \\
\hline $\begin{array}{l}\text { AORTIC AIx (AP/PP) } \\
\text { Mean }\end{array}$ & $8.7(9.4)$ & $18.9(9.5)$ & $<0.001$ & $17.0(10.9)$ & $14.6(9.0)$ & 0.178 & $15.3(10.0)$ & $17.7(10.9)$ & 0.341 \\
\hline $\begin{array}{l}\text { AORTIC AIx (P2/P1) } \\
\text { Mean (SD) }\end{array}$ & $110.4(11.6)$ & $125.7(15.9)$ & 0.001 & $123.3(17.1)$ & $118.6(13.4)$ & 0.301 & $120.3(14.7)$ & $123.9(18.2)$ & 0.373 \\
\hline $\begin{array}{l}\text { PWV (cut-off) } \\
\text { Mean (SD) }\end{array}$ & $8.1(1.1)$ & $8.9(1.3)$ & 0.010 & $8.7(1.2)$ & $8.7(1.4)$ & 0.882 & $8.5(1.4)$ & $9.0(1.2)$ & 0.136 \\
\hline SBP & & & 0.177 & & & 0.300 & & & \\
\hline Mean (SD) & $114.1(11.3)$ & $119.5(20.0)$ & & $117.0(15.9)$ & $122.4(24.4)$ & & $115.1(13.5)$ & $122.0(22.7)$ & 0.121 \\
\hline \multicolumn{10}{|l|}{$\mathrm{DBP}$} \\
\hline Mean (SD) & $70.6(15.4)$ & $75.8(13.1)$ & 0.178 & 74.4 (13.7) & $73.8(14.3)$ & 0.826 & $73.3(14.2)$ & $76.1(13.3)$ & 0.414 \\
\hline
\end{tabular}

stiffness measures, whereas the mean IMT may be a late marker, so that its detection requires a longer follow up.

Markers of early atherosclerosis were overrepresented in our IBD patients, in spite of the low prevalence of traditional cardiovascular risk factors. Indeed, in our study, IBD patients and control group did not show differences in the prevalence of smoking, diabetes and hypertension, and furthermore, body mass index values and total cholesterol and LDL-cholesterol levels were lower in IBD patients than in controls. This clinical scenario, defined by Zanoli "the IBD paradox" [30], has been already introduced in the epidemiological study carried on by Yarur [16], in which 356 IBD patients and 712 controls have been studied for a median of 53 months. In this study, the reported incidence of developing coronary artery disease in the IBD group was significantly higher $(2.85 ; 95 \% \mathrm{CI} 1.82-4.46)$, even though the incidence of smoking, hypertension, diabetes and overweight was low. It seems that traditional and non-traditional risk factors, such as white blood cell count, haemoglobin, ESR, CRP, markers of systemic chronic inflammation, could have a different impact on the incidence of cardiovascular events in IBD and non-IBD patients. Therefore, the key clinical question is whether the incidence of cardiovascular events in these patients is mainly due to early atherosclerosis per se (increasing of all stiffness parameters) or to persistent inflammation, which could contribute to the atherosclerotic process through the maintenance of endothelial dysfunction. Indeed, IBD patients are carriers of a significant inflammatory background, as shown by altered level of CRP, and the pivotal role of inflammation in the onset of atherosclerosis has been confirmed by previous studies, and has been also correlated with the level of proinflammatory cytokines [36,37]. In addition, it has been also reported that high levels of such cytokines, selectins and adhesion molecules were strongly related to the "markers" of arterial stiffness in patients suffering from cerebrovascular events [37,38]. Taken together, these data suggest that inflammation not only is strictly related to markers of arterial stiffness, but also is responsible of the raised atherogenic risk of these patients and, thus of cardio and cerebrovascular events in long-term exposed subjects.

In accordance with this hypothesis, Rungoe et coll [17], showed in the Danish cohort study that long-term risk of cardiovascular event in IBD patients was modified by treatment with 5 -aminosalicilyc acids (5-ASA) and other interventions reducing the inflammatory burden of intestinal disease. In our study we could not demonstrate differences in vascular parameters among patients treated with steroids, immunomodulators or biologics. A statistically significant correlation has been found only for patients treated with 5-ASA, who showed an increase in central AIx. A possible explanation could be that 5-ASA is not enough effective in the control of inflammation in these patients. The increased values of AIx in patients on stable maintenance with 5-ASA only, are in keeping with the results obtained by Zanoli et coll [30], showing that at least one parameter related to aortic stiffness, PWV, did increase over time in patients treated with salicylates as compared to those on longterm treatment with immunomodulating drugs. These data support the hypothesis of a need for a powerful anti-inflammatory intervention in IBD for preventing atherosclerosis and its consequences. Indeed, the

Table 4

Relationship between pharmacological therapy and haemodynamic measurements among IBD patients.

\begin{tabular}{|c|c|c|c|c|c|c|c|c|c|}
\hline & $\begin{array}{l}\text { No Steroids } \\
(50)\end{array}$ & $\begin{array}{l}\text { Steroids } \\
(18)\end{array}$ & $P$ & $\begin{array}{l}\text { No 5-ASA } \\
(20)\end{array}$ & $\begin{array}{l}5-\mathrm{ASA} \\
(48)\end{array}$ & $P$ & $\begin{array}{l}\text { No Imm/Bio } \\
\text { (39) }\end{array}$ & $\begin{array}{l}\mathrm{Imm} / \mathrm{Bio} \\
(29)\end{array}$ & $P$ \\
\hline Carotid IMT mean (mm) & & & & & & & & & 0.587 \\
\hline Right (range) & $0.5(0.2)$ & $0.5(0.1)$ & 0.552 & $0.5(0.1)$ & $0.5(0.2)$ & 0.347 & $0.5(0.1)$ & $0.5(0.2)$ & 0.789 \\
\hline Left (range) & $0.5(0.2)$ & $0.5(0.1)$ & 0.787 & $0.5(0.1)$ & $0.5(0.2)$ & 0.416 & $0.5(0.2)$ & $0.5(0.1)$ & \\
\hline \multicolumn{10}{|l|}{ Carotid Plaque } \\
\hline No & 17 & 43 & & 18 & 42 & & 35 & 25 & \\
\hline Yes & 1 & 7 & 0.340 & 2 & 6 & 0.771 & 4 & 4 & 0.654 \\
\hline $\begin{array}{l}\text { AORTIC AIx (AP/PP) } \\
\text { Mean (SD) }\end{array}$ & $17.1(10.6)$ & $14.3(9.9)$ & 0.338 & $11.9(9.7)$ & $18.2(10.2)$ & 0.021 & $15.9(8.8)$ & $16.9(12.4)$ & 0.704 \\
\hline $\begin{array}{l}\text { AORTIC AIx (P2/P1) } \\
\text { Mean (SD }\end{array}$ & $123.1(16.9)$ & $118.3(14.5)$ & 0.287 & $114.8(13.6)$ & $124.8(16.6)$ & 0.019 & $121.1(13.9)$ & $123.0(19.3)$ & 0.652 \\
\hline $\begin{array}{l}\text { PWV (cut-off) } \\
\text { Mean (SD }\end{array}$ & $8.8(1.3)$ & $8.4(1.3)$ & 0.258 & $8.3(1.2)$ & $8.9(1.3)$ & 0.096 & $8.6(1.4)$ & $8.9(1.2)$ & 0.349 \\
\hline \multicolumn{10}{|l|}{ SBP } \\
\hline Mean (SD) & $117.8(16.2)$ & $119.1(23.7)$ & 0.797 & $114.7(18.4)$ & $119.6(18.3)$ & 0.320 & $115.8(17.6)$ & $121.3(19.1)$ & 0.222 \\
\hline \multicolumn{10}{|l|}{ DBP } \\
\hline Mean (SD) & $75.0(14.7)$ & $73.1(11.4)$ & 0.619 & $71.1(11.0)$ & $75.9(14.7)$ & 0.190 & $72.4(12.7)$ & $77.4(14.8)$ & 0.141 \\
\hline
\end{tabular}


ECCO guidelines [39] for the management of $C D$, have minimized the role of 5-ASA in the maintenance of remission for its limited efficacy showed by randomized clinical trials and meta-analyses [40]. Though being effective in the maintenance of remission of mild-to-moderate UC and possibly effective in chemoprevention, in other indications the role of 5-ASA is questioned and definitely not enough for the proper control of inflammation in Crohn's Disease.

The effect of medications on vascular parameters has not been confirmed by Ozturk et al. [31] though this could be explained by a more relevant proportion of UC patients in their cohort, thus on maintenance therapy with 5-ASA, which in UC could lead to an adequate control of inflammation.

Results of our cross-sectional study in agreement with the prospective, though median follow-up was limited to 3.4 years, pilot study of Zanoli et coll [30], suggest the absence of a protective role of 5-ASA on reducing cardiovascular risk. However, a simple association by chance, because of the small sample size, cannot be discarded. The role of 5-ASA should be assessed in an interventional prospective trial on an adequate patients sample and for an extended period of time. Since most patients were on multiple therapies is not possible to exclude positive or negative effect of the contemporary administration of two or more drugs. A further confirm of our results comes from the paper of dos Santos and colleagues [41], who found that women with UC in clinical remission still have a higher risk for development of atherosclerosis compared to the controls, but "women treated with azathioprine seem more protected than those treated only with aminosalicylates, due to better regulation of the inflammatory process".

This study may have some limitations. First, a larger number of subjects could be necessary to perform with sufficient power subgroup analyses in patients with CD or UC, as well as in those with active disease or in remission. Secondly, to endorse the role of inflammation, a further control group of subjects with other chronic inflammatory disorders such as rheumathoid arthritis or ankylosing spondylitis would have been useful though difficult to match especially for age. Published data in the setting of rheumatologic disorders [42-43], including also a recent paper of our group [44], confirm the increased rate of early alterations of elastic properties of the arterial wall in a cohort of patients of the same ethnic origin. The single head-to-head comparison study published so far on expression of atherosclerosis markers in intestinal and rheumatological inflammatory disease, while confirming higher stiffness values in both conditions, points toward a major role of traditional risk factors [45]. Thirdly, we did not investigate the possibility that a genetic predisposition that is not only limited to IBD may be at the base of the risk of cardiovascular disease and specifically to atherosclerosis in our cohort. Finally, we do not have a follow-up long enough to evaluate the effect of immunomodulators on the incidence of cardiovascular events. This requires a long time since, in our cohort, until now, no cardio and/or cerebrovascular events has been observed. We believe that a re-assessment of the hemodynamic parameters in the follow-up of IBD patients at fixed intervals (maybe three or five years time), in relation to the course of disease (remission/relapse) and pharmacological treatments, could provide better information to discriminate the impact of immunosuppressive drugs and/or biologics on the atherosclerotic process.

However, we believe our findings have clinical relevance because contribute to expand previous knowledge about the pathogenic mechanisms underlying the high prevalence of cardiovascular morbidity and mortality in patients with chronic systemic inflammatory disease. In fact, there are consolidated evidences demonstrating that abnormal arterial stiffness, reflecting the arterial wall modifications, is a powerful and independent predictor for various adverse cardiovascular outcomes [46-47]. In rheumatologic disease, it is a common practice to monitor patients for the development of early atherosclerosis markers to assure early recognition and management of cardiovascular disease. In IBD evidence is still limited, mechanisms have not been fully elucidated [46] and practice guidelines are not available and maybe it is still questionable if they are needed, as suggested in the recent review by Rungoe et al. [48]. Wu and coworkers, however, in a very recent meta-analysis support the clinical utility of markers of subclinical atherosclerosis in the management of IBD patients [49]. We think our work adds further information toward a modification of standard clinical practice. The absence of a protective role of 5-ASA, in spite of its potential aspirin-like properties, could have clinical implications meaning that reducing the burden of inflammation with earlier use of more potent and potentially disease-modifying drugs, able to obtain not only symptomatic improvement but also mucosal healing and deep remission, is the key end-point of IBD management to improve all outcomes. Management strategies in IBD should definitely look "beyond symptoms" and aim to heal the mucosa in order to prevent bowel damage, disability and maybe reverse cardiovascular risk [50].

In conclusion, in our study, we have shown the expression of markers of early atherosclerosis in young patients with IBD. Larger longitudinal studies are needed to better evaluate the correlation between indices of subclinical atherosclerosis, and clinical, biochemical signs of systemic inflammation and reliable markers for the healing of the mucosa in subgroups exposed to different drugs in order to target therapeutic interventions.

Supplementary data to this article can be found online at doi:10. 1016/j.ejim.2016.10.004.

\section{Conflict of interest disclosure}

The authors declare no conflicts of interests. None of the authors have any financial or other relations that could lead to a conflict of interest.

\section{Acknowledgements}

M Cappello and A Licata designed the study, contributed to data acquisition, were responsible for writing the article, and participated in statistical analysis. I Bravatà, A Aiello, V. Della Corte, A. Tuttolomondo and D. Torres participated in patients' management, data acquisition and collection. V Calvaruso and C Cammà performed statistical analysis. M Cappello, A Licata, M Perticone, G. Licata, C Cammà and A. Craxì (Director of the GI \& Liver Unit) were responsible for the project and critical revision of the manuscript. All authors have seen and approved the final version of the article.

\section{References}

[1] Baumgart DC, Carding SR. Inflammatory bowel disease: cause and immunobiology. Lancet 2007;369:1627-40.

[2] Wakefield AJ, Sawyerr AM, Dhillon AP, et al. Pathogenesis of Crohn's disease: multifocal gastrointestinal infarction. Lancet 4 1989;2(8671):1057-62.

[3] Bernstein CN, Blanchard JF, Houston DS, et al. The incidence of deep venous thrombosis and pulmonary embolism among patients with inflammatory bowel disease: a population-based cohort study. ThrombHaemost 2001;85(3):430-4.

[4] Ross R. Atherosclerosis an inflammatory disease. N Engl J Med 14 1999;340(2): 115-26.

[5] Laroux FS, Grisham MB. Immunological basis of infiammatory bowel disease: role of microcirculation. Microcirculation 2001;8(5):283-301.

[6] Libby P, Ridker PM, Maseri A. Inflammation and atherosclerosis. Circulation 5 2002; 105(9):1135-43.

[7] Paoletti R, Gotto Jr AM, Hajjar DP. Inflammation in atherosclerosis and implications for therapy. Circulation 15 2004;109(23 Suppl. 1):III20-6.

[8] Hatoum OA, Binion DG. The vasculature and inflammatory bowel disease: contribution to pathogenesis and clinical pathology. Inflamm Bowel Dis 2005;11(3):304-13.

[9] Papa A, Danese S, Urgesi R, et al. Early atherosclerosis in patients with inflammatory bowel disease. Eur Rev Med Pharmacol Sci Jan-Feb 2006;10(1):7-11.

[10] Ross R. The pathogenesis of atherosclerosis: a perspective for the 1990s. Nature Apr 29 1993;362(6423):801-9.

[11] Libby P, Ridker PM, Hansson GK. Leducq Transatlantic Network on Atherothrombosis. Inflammation in atherosclerosis: from pathophysiology to practice. J Am Coll Cardiol 1 2009;54(23):2129-38.

[12] Van Doornum S, McColl G, Wicks IP. Accelerated atherosclerosis: an extra-articular feature of rheumatoid arthritis? Arthritis Rheum 2002:46(4):862-73.

[13] Selzer F, Sutton-Tyrrell K, Fitzgerald SG, et al. Comparison of risk factors for vascular disease in the carotid artery and aorta in women with systemic lupus erythematosus. Arthritis Rheum 2004;50(1):151-9. 
[14] Södergren A, Karp K, Boman K, et al. Atherosclerosis in early rheumatoid arthritis: very early endothelial activation and rapid progression of intima media thickness. Arthritis Res Ther 2010;12(4):R158.

[15] Dorn SD, Sandler RS. Inflammatory bowel disease is not a risk factor for cardiovascular disease mortality: results from a systematic review and meta-analysis. Am J Gastroenterol 2007;102(3):662-7.

[16] Yarur AJ, Deshpande AR, Pechman DM, et al. Inflammatory bowel disease is associated with an increased incidence of cardiovascular events. Am J Gastroenterol 2011;106(4):741-7.

[17] Rungoe C, Basit S, Ranthe MF, et al. Risk of ischaemic heart disease in patients with inflammatory bowel disease: a nationwide Danish cohort study. Gut 2013;62(5): 689-94.

[18] Osterman MT, Yang YX, Brensinger C, et al. No increased risk of myocardial infarction among patients with ulcerative colitis or Crohn's Disease. Clin Gastroenterol Hepatol 2011;9(10):875-80.

[19] Gandhi S, Narula N, Marshall JK, et al. Are patients with inflammatory bowel disease at increased risk of coronary artery disease? Am J Med 2012;125(10):956-62.

[20] Kristensen SL, Ahlehoff O, Lindhardsen J, et al. Disease activity in inflammatory bowel disease is associated with increased risk of myocardial infarction, stroke and cardiovascular death-a Danish nationwide cohort study. PLoS One 2013;8(2): e56944.

[21] Papa A, Santoliquido A, Danese S, et al. Increased carotid intima-media thickness in patients with inflammatory bowel disease. Aliment Pharmacol Ther 1 2005;22(9): 839-46.

[22] Broide E, Schopan A, Zaretsky M, et al. Intima-media thickness of the common carotic artery is not significantly higher in Crohn's disease patients compared to healthy population. Dig Dis Sci 2011;56(1):197-202.

[23] Maharshak N, Arbel Y, Bornstein NM, et al. Inflammatory bowel disease is not associated with increased intimal media thickening. Am J Gastroenterol 2007;102(5): 1050-5.

[24] Dagli N, Poyrazoglu OK, Dagli AF, et al. Is inflammatory bowel disease a risk factor for early atherosclerosis? Angiology 2010;61(2):198-204.

[25] Kayahan H, Sari I, Cullu N, Yuksel F, Demir S, Akarsu M, et al. Evaluation of early atherosclerosis in patients with inflammatory bowel disease. Dig Dis Sci Aug 2012;57(8):2137-43.

[26] Schinzari F, Armuzzi A, De Pascalis B, Mores N, Tesauro M, Melina D, et al. Tumor necrosis factor-alpha antagonism improves endothelial dysfunction in patients with Crohn's disease. Clin Pharmacol Ther Jan 2008;83(1):70-6.

[27] Aloi M, Tromba L, Di Nardo G, Dilillo A, Del Giudice E, Marocchi E, et al. Premature subclinical atherosclerosis in pediatric inflammatory bowel disease. J Pediatr 2012; 161(4):589-94.

[28] Principi M, Mastrolonardo M, Scicchitano P, Gesualdo M, Sassara M, Guida P, et al. Endothelial function and cardiovascular risk in active inflammatory bowel diseases. J Crohn's Colitis 1 2013;7(10):e427-33.

[29] Zanoli L, Cannavò M, Rastelli S, Di Pino L, Monte I, Di Gangi M, et al. Arterial stiffness is increased in patients with inflammatory bowel disease. J Hypertens 2012;30(9): 1775-81.

[30] Zanoli L, Rastelli S, Inserra G, Lentini P, Valvo E, Calcagno E, et al. Increased arterial stiffness in inflammatory bowel diseases is dependent upon inflammation and reduced by immunomodulatory drugs. Atherosclerosis Jun 2014;234(2):346-51.

[31] Ozturk K, Kuler AM, Cakir M, Ozen A, Demirci H, Turker T, et al. Pulse wave velocity, intima media thickness, and flow-mediated dilatation in patients with normotensive normoglycemic inflammatory bowel disease. Inflamm Bowel Dis 2015;21:1314-20.

[32] Rutgeerts P, Sandborn WJ, Feagan BG, Reinisch W, Olson A, Johanns J, et al. Infliximab for induction and maintenance therapy for ulcerative colitis. N Engl J Med Dec 8 2005;353(23):2462-76.
[33] Harvey RF, Bradshaw MJ. Measuring Crohn's disease activity. Lancet May 24 1980; 1(8178):1134-5.

[34] Tuttolomondo A, Di Raimondo D, Di Sciacca R, Pecoraro R, Arnao V, Buttà C, et al. Arterial stiffness and ischemic stroke in subjects with and without metabolic syndrome. Atherosclerosis 2012;225(1):216-9.

[35] Kovaite M, Petrulioniene Z, Ryliskyte L, Badariene J, Dzenkeviciute V, Cypiene A, et al. Systemic assessment of arterial wall structure and function in metabolic syndrome. Proc West Pharmacol Soc 2007;50:123-30.

[36] Tuttolomondo A, Pecoraro R, Di Raimondo D, Di Sciacca R, Canino B, Arnao V, et al. Immune-inflammatory markers and arterial stiffness indexes in subjects with acute ischemic stroke with and without metabolic syndrome. Diabetol Metab Syndr Feb 27 2014;6(1):28

[37] De Silva DA, Woon FP, Gan HY, Cameron J, Kingwell B, Koh TH, et al. Arterial stiffness, metabolic syndrome and inflammation amongst Asian ischaemic stroke patients. Eur J Neurol 2008;15(8):872-5.

[38] Kampus R, Kals J, Ristimae T, Fischer K, Zilmer M, Teesalu R. High sensitivity C-reactive protein affects central hemodynamics and augmentation index in apparently healthy persons. J Hypertens 2004;22:1133-9.

[39] Dignass A, Van Assche G, Lindsay JO, Lémann M, Söderholm J, Colombel JF, et al. The second European evidence-based consensus on the diagnosis and management of Crohn's disease: current management. Journal of Crohn's and Colitis 2010;4(1): 28-62.

[40] Ford AC, Kane SV, Khan KJ, Achkar JP, Talley NJ, Marshall JK, et al. Efficacy of 5-aminosalicylates in Crohn's disease: systematic review and meta-analysis. Am J Gastroenterol 2011;106(4):617-29.

[41] dos Santos LC, Costa AV, Lopes LG, et al. Combination of azathioprine and aminosalicylate treatment prevent risk of cardiovascular disease in women with ulcerative colitis by reducing inflammation. Med Sci Monit 2015;21:2305-15.

[42] Tuttolomondo $A$, Pecoraro $R$, Buttà $C$. Di Raimondo D, Ferrante $A$, Della Corte V et al. Arterial stiffness indexes and serum cytokine levels in seronegative spondyloarthritis: relationships between stiffness markers and metabolic and immunoinflammatory variables. Scand J Rheumatol 2015;14:1-6.

[43] Temiz A, Gökmen F, Gazi E, Akbal A, Barutçu A, Bekler A, et al. Epicardial adipose tissue thickness, flow-mediated dilatation of the brachial artery, and carotid intima-media thickness. Associations in rheumatoid arthritis patients. Herz 2015; 40(Suppl. 3):217-24.

[44] Fan F, Galvin A, Fang L, et al. Comparison of inflammation, arterial stiffness and traditional cardiovascular risk factors between rheumatoid arthritis and inflammatory bowel disease. J Inflamm 2014;11:29.

[45] Willum-Hansen T, Staessen JA, Torp-Pedersen C, Rasmussen S, Thijs L, Ibsen H, et al. Prognostic value of aortic pulse wave velocity as index of arterial stiffness in the general population. Circulation 2006; 113:664-70.

[46] Mattace-Raso FU, van derCammen TJ, Hofman A, van Popele NM, Bos ML Schalekamp MA, et al. Arterial stiffness and risk of coronary heart disease and stroke: the Rotterdam Study. Circulation 2006;113:657-63.

[47] Schicho R, Marsche G, Storr M. Cardiovascular complications in inflammatory bowel disease. Curr Drug Targets 2015;16(3):181-8.

[48] Rungoe C, Andersen NN, Jess T. Inflammatory bowel disease and risk of coronary heart disease. Trends in cardiovascular medicine 2015:1050-738. http://dx.doi.org/ 10.1016/j.tcm.2015.03.010

[49] Wu GC, Leng RX, Lu Q, Fan YG, Wang DG, Ye DQ. Subclinical atherosclerosis in patients with inflammatory bowel diseases: a systematic review and meta-analysis. Angiology Jun 12016 [pii: 0003319716652031 ] [Epub ahead of print].

[50] Sandborn WJ, Hanauer S, Van Assche G, et al. Treating beyond symptoms with a view to improving patient outcomes in inflammatory bowel diseases. Journal of Crohn's and Colitis 2014;8:927-35. 